\title{
La Criatura de Frankenstein y la lucha por el reconocimiento
}

\author{
ANA HARDISSON RUMEU \\ (IES Anaga, Sta. Cruz de Tenerife)
}

\begin{abstract}
Resumen. Este texto de Mary Shelley permite la posibilidad de considerar el personaje de la «Criatura» desde la perspectiva de la Ética del reconocimiento, de Axel Honneth. Desde este punto de vista, la carga dramática de esta novela gira en torno al problema de la identidad. La condición imprescindible para construir la identidad es el reconocimiento por parte del otro. Por eso la identidad no se puede adquirir en el plano subjetivo de la conciencia solitaria, sino que precisa de la intersubjetividad. La criatura se ve privada de reconocimiento, incluso por parte de Frankenstein, que lo ha engendrado. Esa privación, al negarle el derecho más elemental del ser humano, que es ser alguien y tener una identidad, lo vuelve perverso. Su maldad es el efecto secundario de la marginación y el sufrimiento.
\end{abstract}

La novela de Mary Shelley Frankenstein suele interpretarse como una novela gótica, propia del Romanticismo, que crea la imagen del nuevo Prometeo. Actualmente, la investigación científico-técnica y las posibilidades abiertas por la ingeniería genética son las claves de este renovado mito ${ }^{1}$. Sin duda esa crítica y esa llamada de atención ante los riesgos de una tecnología desbocada, sin principios éticos que la dirijan, constituyen una aportación fundamental de esta novela. Sin embargo, me gustaría proponer una segunda lectura que, sin descalificar ésta que hemos citado, pudiera ampliar las perspectivas de su interpretación. Se trata de poner el acento
ABSTRACT. This text of Mary Shelley permits the possibility of considering the character of the «Creature» from the Axel Honneth's perspective of the Ethics of reconnaissance. From this point of view, the dramatic sense of this novel moves round identity's problem. The essential condition to build identity is the recognition from each to other. That is why identity can not be obtain in the sense of solitarious consciousness, but requires of intersubjetivity. The Creature becomes deprived of recognition, even by Frankenstein who has created him. This Creature becomes perverse because this privation, when the most elemental right of human being so as being someone and having an identity, is denied to him. His wickedness is the secondary effect of exclusion and suffering.

en el personaje de la Criatura, ese oscuro sujeto sin nombre, aparentemente gris y segundón, pero que, desde una nueva perspectiva, podría propiciar un análisis que lo sitúe más allá de ser un instrumento para subrayar las peripecias del Dr. Frankenstein. Voy a proponer que imaginemos que la Criatura es el personaje verdaderamente protagonista de esta historia.

Desde este punto de mira, esta novela ya no es principalmente una novela de terror, con paisajes siniestros y castillos tenebrosos, que los tiene, sino que ahora se nos muestra en una nueva dimensión. Se trata de un relato que plantea el problema de la identidad humana y de la nece- 
sidad de ser reconocido por los otros. El drama que nos presenta esta historia se desarrolla más en la lucha interior de la Criatura que en los horrores externos que se narran. Para ejemplificar esto, empezaré por hacer una referencia al argumento.

En esta obra un marino, Robert Walton, le escribe a su hermana una historia que le ha contado un científico, llamado Victor Frankenstein, acerca de la creación de un monstruoso ser, que ha sembrado toda su vida de horror y sufrimiento, a su vez, el personaje sin nombre, La Criatura, tendrá ocasión de hablar por sí misma, a la muerte de Frankenstein, su creador.

Victor Frankenstein, joven estudiante de ciencias naturales, fascinado por la química y los experimentos de electricidad, así como por las recientes teorías del origen de la vida, concibe el sueño de crear una nueva especie de hombres más hermosos y armónicos que los existentes, quienes le reconocerán como a su padre y hacedor y pasará por ello a la posteridad. Durante dos años se entrega día y noche a sus investigaciones y experimentos juntando fragmentos de cadáveres, elegidos por su hermosura, para fabricar a la nueva Criatura. Por fin culmina el proceso y la Criatura cobra vida. Pero desde que ésta abre sus vidriosos ojos amarillentos Frankenstein desarrolla un tremendo rechazo por su «hijo» que le produce horror. $\mathrm{El}$ ser que acaba de crear le parece monstruoso. Espantado abandona a su criatura sin darle ni oportunidad ni tiempo de manifestarse. Sin transmitirle ningún afecto paternal, sin intentar enseñarle ningún rasgo de su cultura o de sus creencias. Simplemente, huye y la deja abandonada a su suerte.

2 La Criatura se verá obligada a sobrevivir sola, por sus propios medios. Este ser de apariencia diferente, por lo que es considerado monstruoso, deberá vivir escondido de la mirada de los hombres, a quienes atemoriza sin pretenderlo y sin comprender por qué. Ella desea la compañía, el afecto y la aceptación de los otros, a los que considera sus semejantes, siente una gran admiración por los seres humanos a los que desea ayudar. Quiere vivir con ellos integrado como uno más. Pero cada vez que intenta acercarse todos salen corriendo despavoridos o le atacan y le maltratan con el pretexto de que temen que sea peligroso.

Entonces aprende a vivir sin ser visto escondiéndose de los humanos, pero observándolos para aprender de ellos. Tiene una enorme curiosidad y deseos de saber, de forma autodidacta aprende las costumbres y el lenguaje, pero no le sirven de mucho porque sólo inspira temor. Ante esta situación de soledad y sufrimiento insoportables decide ir a ver a su creador, a su padre, para pedirle que le proporcione una compañera. Necesita alguien con quien compartir la vida, alguien que le reconozca como a un igual y que pueda amarle. Comprensión y afecto son requisitos imprescindibles para poder tener una vida buena.

Frankenstein, en un principio, parece entender el drama de su criatura y acepta compadecido por la inmensa soledad de la Criatura que él ha creado, pero que no ha reconocido como obra suya, sino que ha abandonado sin ni siquiera haberle dado un nombre. Pero a la hora de la verdad se niega a darle una compañera, a repetir el proceso de la creación, argumentando que no tiene la seguridad de que ese nuevo ser no resulte una criatura perversa que pudiera poner en peligro la integridad de los humanos, a los que se siente en el deber de proteger.

Así pues, este ser condenado al ostracismo por su creador, a quien se le ha negado todo derecho, incluso el más elemental de la identidad humana que es el poseer un nombre, al sentirse irremediablemente condenado a la soledad, promete venganza:

«Me vengaré de mis sufrimientos, si no puedo inspirar amor, desencadenaré el miedo; y espe- 
cialmente a ti, mi supremo enernigo, por ser mi creador, te juro odio eterno»?

A partir de este momento, después de haber intentado por todos los medios que su creador le concediese una compañera con razonamientos que apelaban a la justicia y que hubieran conmovido al ser más insensible, palabras llenas de sensatez y sentimiento como: «Yo era bueno y cariñoso; el sufrimiento me ha envilecido. Concededme la felicidad, y volveré a ser virtuoso» ${ }^{3}$. O estas otras: «yo era bueno; mi espíritu estaba lleno de amor y humanidad, pero estoy solo, horriblemente solo» ${ }^{4}$. Al fracasar en su desesperado intento se convierte en un criminal y comete los más terribles asesinatos de jóvenes, niños e inocentes, empezando por la misma familia de Frankenstein. Este decide ir a su encuentro para matarlo. Comienza, entonces, la persecución en la que no se sabe con claridad quién persigue a quién y quién guía al otro. Después de terribles peripecias y penalidades muere Frankenstein, agotado y enfermo, en los glaciares del Polo Norte.

La criatura llora arrepentida la muerte de su padre, al que amaba, a pesar de los desprecios y malos tratos que siempre había recibido de él, y promete morir a su vez. Ha comprendido que la venganza no era el camino de la liberación. Su naturaleza bondadosa no le permite aceptar los crímenes que ha cometido y, abrumado por el peso de los remordimientos, «se perdió en la oscuridad y en la distancia».

\section{Elementos para una lectura desde la lucha por el reconocimiento :}

La referencia a la lucha por el reconocimiento tiene sus raíces en la teoría hegeliana, no sólo en la Fenomenología del Espíritu $^{5}$, sino, también, en el sistema de Jena. Hegel explica el origen de la sociedad como una lucha por el reconocimiento intersubjetivo en la que el deseo de ser reconocido por otro es imprescindible para poder acceder a la autoconciencia. Esto lleva a los hombres a poner en riesgo su vida enfrentándose a una lucha a muerte. Como resultado de esa lucha el más débil devendrá esclavo del otro. Es así como comienza la desigualdad entre los hombres que quedarán divididos en dos categorías: amo y esclavo. Habermas retomará la veta hegeliana del reconocimiento ${ }^{6}$. A partir de esta reapropiación ${ }^{7}$, Axel Honneth realiza un sugerente estudio sobre la lucha por el reconocimiento, elemento que nos presenta como núcleo fundamental de los conflictos morales, que me ha servido de marco teórico para el análisis del personaje de Mary Shelley.

Según Honneth, el reconocimiento intersubjetivo es el fundamento de la moral $y$ ese fundamento ético es considerado como la base normativa de la explicación social ${ }^{8}$. Existen tres tipos de reconocimiento recíproco necesarios para que sea posible acceder a la identidad y tener una vida buena. El primero debe producirse en las relaciones afectivas de la infancia, en el reconocimiento de la familia y produce la autoconfianza. El segundo depende de las leyes de la sociedad civil, que garantizan el reconocimiento jurídico, el sujeto es reconocido como una persona abstracta. Este reconocimiento legal produce el autorrespeto. El tercero alude al reconocimiento de un sujeto socializado en su unicidad. En este nivel el sujeto adquiere el reconocimiento público de su valor como persona. En esta esfera se asienta la solidaridad de la cultura compartida. Es el nivel de los valores y de él depende la autoestima? .

El personaje de la Criatura, que nos presenta Mary Shelley, ha sido privado de las tres formas de reconocimiento, que hace un momento mencionaba, empezando por el más básico como es el afecto de los padres, es un hijo rechazado y abandonado a causa de su apariencia diferente, a-nor- 
mal y deforme ${ }^{10}$. El padre no acepta a ese ser no sometido a las reglas de lo establecido y, porque no muestra ningún parecido con él, lo rechaza y lo abandona a su suerte. Su anomalía, su diferencia lo condena al ostracismo y a la soledad, por lo que tendrá que arreglárselas sin apoyo de ningún tipo para sobrevivir y realizar su aprendizaje de forma autodidacta. El basamento afectivo del reconocimiento colapsa ante el abandono ${ }^{11}$. Sin este fundamento afectivo ¿cómo podría producirse una socialización satisfactoria?

¿Cuantas niñas no se habrán sentido rechazadas por sus padres, por no tener la imagen adecuada, o por no ser el varoncito esperado? La propia Mary Shelley parece que sufrió una situación similar, ya que su padre, William Godwin, nunca demostró demasiado afecto e interés por su hija, ni le proporcionó la educación que su madre, Mary Wollstonecraft, había reclamado para todas las niñas en igualdad de condiciones con los niños ${ }^{12}$. Así que Mary, como la Criatura, tuvo que aprender sola.

Por otra parte, ese ser llamado «monstruo», descalificado por su creador, no reconocido por su padre: «desde el principio demostró la bondad de sus sentimientos, su necesidad de afecto y una enorme sed de conocimiento acerca de su origen y del mundo que le rodeaba" ${ }^{13}$. Él, ¿o debemos llamarle ella?, ignoraba que era monstruoso y no entendía el rechazo que la gente le mostraba hasta que se vio reflejado en las aguas de un estanque y observó lo diferente que era. Entendió entonces el horror que causaba a los demás: su aspecto era diferente y lo distinto asusta a los hombres. De esta manera emerge, en toda su dimensión, el terrible problema de la identidad y el reconocimiento. El papel de los otros como espejo necesario para captar la propia imagen, la identidad como una construcción intersubjetiva, $y$, en definitiva, el reconocimiento de los otros como condición del propio reconocimiento. Como dice Honneth:

«La reproducción de la vida social se cumple bajo el imperativo de un reconocimiento recíproco, ya que los sujetos sólo pueden acceder a una autorrealización práctica si aprenden a concebirse a partir de la perspectiva normativa de sus compañeros de interacciónss ${ }^{14}$.

En la identidad se alojan dos aspectos fundamentales y complementarios: el ser y el aparecer, la entidad y las representaciones, la esencia y las máscaras. La identidad está formada por fragmentos como la propia Criatura. En su percepción interna e íntima ella se siente buena y desea amar y ser amada, pero al reconocerse a través de la mirada de los otros se descubre perversa y monstruosa.

$Y$ en esta desolada situación se plantea las preguntas claves de la existencia humana: «¿Quién era yo?, ¿qué era?, ¿de dónde venía?, ¿cuál era mi destino?». Estas preguntas encierran todo el sentido de la vida: la subjetividad, la entidad, el origen y la finalidad. La búsqueda de la identidad es la fuente de toda inquietud y temor internos, especialmente para aquellos a quienes se les niega desde el exterior, como le ocurría a la Criatura y como le ocurre a los excluidos por sus diferencias raciales, sexuales, culturales, ya que

«.. el sujeto adulto, por la experiencia del reconocimiento jurídico, conquista la posibilidad de concebir su obrar como una exteriorización, respetada por todos, de la propia autonomías ${ }^{15}$.

La carencia de identidad de este atormentado personaje es la que nos acerca a la situación de las mujeres consideradas como lo radicalmente otro, como la alteridad ajena por excelencia tal como puso de manifiesto Simone de Beauvoir. De igual forma, nos pone en contacto con todos los grupos perseguidos por sus diferencias, ya sean de etnia, de religión, de sexo, de cultura o de cualquier otra índole. 
Por lo que la criatura de Frankenstein se constituye en un símbolo contra toda discriminación por razón de la diferencia.

En este relato podemos observar cómo la opinión que Frankenstein y la sociedad establecida tienen sobre la Criatura no concuerda con lo que ella siente y piensa de sí misma. La imagen tópica establecida y aceptada por todos es antagónica a la imagen que ella tiene de sí misma. Los prejuicios se esgrimen como argumentos, las opiniones no se apoyan en la observación y en la comprensión de la situación, sino que se condena y se rechaza a este ser, de antemano, por su apariencia.

Mary Shelley le da la oportunidad de tomar la palabra y contrastar su versión con la de su hacedor. Ésa es la clave para avanzar en la dirección de la ética del reconocimiento: dejar hablar al otro, no hablar en su nombre, sino darle la palabra. Y por esto el texto de Shelley puede ser leído como una denuncia del reverso del reconocimiento, esto es, del abandono, de la exclusión y del desprecio. Un ejemplo de esto puede ser el de la identidad de la mujer, definida por su «hacedor» como ángel doméstico, lo que supone la disolución de las individualidades en un genérico femenino caracterizado sólo por las razones del corazón y sin otro interés que la entrega a los otros. La mujer, desde los mitos primigenios - pensemos en Eva y Pandora- y desde el mismo canon aristotélico, es pensada como defectiva y monstruosa. $\mathrm{Si}$, además, no cumple con las expectativas de la feminidad acuñada por el patriarcado, es estigmatizada como doblemente monstruosa. El castigo que se impone a las infractoras es la falta de consideración y la soledad.

La criatura que crea Victor Frankenstein es rechazada desde el primer instante por su creador a causa de su diferencia; desde el primer contacto decide que un ser $\tan$ «feo», con una apariencia tan extrana, no puede ser bueno. No le da ocasión de expresarse, no le concede ninguna opor- tunidad de ser semejante en su diferencia, no le permite mostrar su intimidad, no se interesa por sus sentimientos. Ante lo distinto no siente curiosidad e interés, sino temor y rechazo. Le condena por su apariencia. Muestra su incapacidad «para sentir al otro como a uno mismo». Frankenstein siente que no responde a sus expectativas y deja de considerarlo como responsabilidad suya. La diferencia se estigmatiza como repulsiva.

Para justificar su abandono y su irresponsabilidad Frankenstein sataniza a la criatura a quien condena como malvada de antemano sin conocerla tal como ocurre, en nuestra sociedad, con todos aquellos que representan alguna diferencia considerable, de color, raza, costumbres, creencias, opción sexual, etc. Con su actitud hostil Frankenstein arrincona a la criatura hasta el extremo de llevarla a cometer actos criminales y despiadados como resultado del sufrimiento, el desprecio y la soledad. No obstante, las perversidades cometidas no logran arruinar su conciencia moral debatiéndose siempre ésta con el arrepentimiento y los remordimientos.

Desde esta lectura, esta novela se nos aparece como una historia acerca de la trágica búsqueda de la identidad y el necesario reconocimiento intersubjetivo para llegar a ser, para convertirse en una persona. Y también, como una crítica a los prejuicios y a las apariencias, a la marginaciốr y a la injusticia de la sociedad excluyente que no reconoce el derecho a la diferencia. En palabras de Isabel Burdiel, deberíamos tender hacia

«Una noción de identidad, sin embargo, que se adivina inevitablemente conflictiva y poblada de fantasmas. Tan sólo el reconocimiento (social $e$ individual) de la propia monstruosidad en tanto que idéntica y distinta a la de los otros que nos acompañan y nos definen podría, quizás, conducir a la libertad del Sens ${ }^{16}$.

La sugerencia de Mary Shelley puede ser leída hoy como una invitación a mostrar 
curiosidad por la alteridad y las diferencias en vez de reaccionar violentamente contra todo aquello que por ser extraño y lejano nos pudiera producir inquietud. El derecho al propio nombre, al acogimiento, a la inclusión y al aprecio se conjugan en la ética del reconocimiento, que no es otra cosa que el humus necesario para que los individuos tengan acceso a una identidad no distorsionada y a una vida digna y plena.

\section{NOTAS}

1 Véase, a título de ejemplo, R. Shattuck, «Fausto y Frankenstein», en Conocimiento prohibido, Madrid, Taurus, 1998, pp. 101-136.

${ }_{2}$ M. Shelley, Frankenstein o el moderno Prometeo, Madrid, Cátedra, 1996, p. 264.

${ }^{3}$ Op. cit., p. 217.

${ }^{4}$ Op. cit., p. 345.

${ }^{5}$ México, FCE, 1966. Traducción de W. Flores, pp. 113-121.

${ }^{6}$ En J. Habermas, «Trabajo e interacción. Notas sobre la filosofía hegeliana del sistema de Jena», en Ciencia y técnica como «ideología", Madrid, Tecnos, 1984. Para un tratamiento del tema del reconocimiento en la obra habermasiana, véase M. J. Guerra, «Modelos de reconocimiento y subtexto de género», en Mujer, identidad y reconocimiento. Habermas y la crítica feminista, Sta. Cruz de Tenerife, Instituto Canario de la Mujer, 1998

$?$ A. Honneth, «Lógica de la emancipación. El legado filosófico del marxismo», en Debats, núm. 37, septiembre 1991.

8 A. Honneth. La lucha por el reconocimiento, Barcelona, Crítica, 1997. Véase también, del mismo autor, «Reconocimiento y obligaciones morales», Revista Internacional de Filosofía Política, núm. 8.

${ }^{9}$ A. Honneth, «Integridad y desprecio. Motivos básicos de una concepción de la moral desde la teoría del reconocimiento», en Isegoría, núm. 5, mayo 1992.

${ }_{10}$ Véase sobre la relación entre bastardía y monstruosidad S. C. Greenfield and C. Barash (eds.), en Inventing maternity: politics, science, and literature 1650-1865, Kentucky, The University Press, 1999.
11 Véase A. Honneth, «Patrones de reconocimiento intersubjetivo: amor, derecho, solidaridad», en op. cit, pp. 114-169. Honneth remite a la teoría de las rela ciones objetales, especialmente a la obra de Winnicott En esta dirección, señala, también, la aportạción de J. Benjamin al dar cuenta del proceso de reconocimiento necesario entre la madre y el niño, aludiendo, además, al papel de la diferencia sexual. A este respecto, véase de esta autora Los lazos del amor. Psicoanálisis, feminismo y el problema de la dominación. Barcelona, Paidós, 1996, y «Reconocimiento y destrucción: un bosquejo de la intersubjetividad», en Sujetos iguales, objetos de amor, Barcelona, Paidós, 1997.

${ }_{12} \mathrm{M}$. Wollstonecraft, Vindicación de los derechos de la mujer, Madrid, Cátedra, 1994. I. Burdiel, Introducción. Véase, también, de la misma autora, «Vindicación de los deseos de la mujer», en A. Mollá (ed.), Después de Marx y Freud, Sta. Cruz de Tenerife, Cabildo Insular de Tenerife, 1999. Isabel Burdiel es la editora de la versión castellana que he utilizado, quien realiza un extraordinario estudio preliminar, con una visión muy cercana a la que ofrezco en estas páginas.

${ }^{13}$ I. Burdiel, «Frankenstein o la identidad monstruosa», en M. Shelley, op. cit., p. 50

${ }_{14}$ A. Honneth, op. cit., p. 114

15 A. Honneth, op. cit., p. 145

16 I. Burdiel, «Frankenstein o la identidad monstruosa», en M. Shelley, op. cit., pp. 92-93. Una interpretación muy similar a ésta es la de E. Goffman, Estigma. La identidad deteriorada, Buenos Aires. Amorrortu, 1989. 